\title{
La variedad lingüística y el cine. Un recurso didáctico para la clase de E/LE
}

\author{
Jorge Roselló VerdegueR \\ Universitat de València \\ Jorge.Rosello@uv.es
}

\begin{abstract}
Resumen. En el presente trabajo realizamos una propuesta didáctica sobre la variación lingüística y cultural tomando como base la película Terrados (2011). Para ello, seleccionamos algunos diálogos de la película con el fin de trabajar sobre las variedades dialectales (interferencias entre español y catalán), las variedades sociales (edad o nivel sociocultural) y, especialmente, los registros (español coloquial). A continuación, también proponemos algunas reflexiones sobre temas sociales en la España actual (la crisis económica, el desempleo, la utilidad de los estudios universitarios, etc.).
\end{abstract}

Palabras clave. Variación lingüística, cine, español para fines específicos, cultura, temas sociales.

Abstract. This paper offers a didactic proposal for linguistic and cultural variation base on the movie Terrados (2011). For this proposal, some dialogues appearing in Terrados are mapped to deal with some dialectal (interferences between Spanish and Catalan) and social varieties (age or sociocultural level), focusing on spoken Spanish. Thus, this paper also involves some social issues, which are nowadays relevant in Spain (economic crisis, unemployment or benefits of college education).

Keywords. Linguistic variation, cinema, Spanish for specific purposes, culture, social issues

\section{Introducción}

Como sabemos, la lengua es variable y así se manifiesta en múltiples contextos. Ocurre en nuestras conversaciones cotidianas y también en el cine porque este refleja la forma de hablar de las personas, lo que nos sitúa ante un laboratorio de primer orden para poder analizar la variación lingüística. En efecto, es muy común que en una película coincidan personajes provenientes de diferentes lugares del mundo hispánico (Argentina, México, España, Cuba) o, de distintas zonas del mismo país (andino, rioplatense o cuyano en Argentina; andaluz, gallego o catalán en España...), por lo que tendremos un buen material para analizar la variación dialectal del español. Pero la variación también puede referirse a elementos sociolingüísticos, ya que no es difícil en una película encontrarse con diferencias en la forma de hablar provenientes de la edad de los personajes o de su diferente estrato social. Por último, es habitual también que un mismo personaje utilice diferentes registros, según esté hablando con sus amigos en el bar o lleve a cabo la defensa de su cliente, por ejemplo, en un juzgado.

Por consiguiente, la visión de una película nos ofrece toda una gama de variantes lingüísticas de una misma lengua, en este caso el español, que pueden ser aprovechadas para un fin didáctico. Pero, para ello, no basta el simple visionado de la película. Hace falta llevar a cabo una estrategia didáctica que plantee actividades concretas, seleccione fragmentos representativos y haga reflexionar al alumnado sobre los contenidos que se 
adquieren a través de la lengua. Porque el aprendizaje de un idioma conlleva también, lo sabemos, la transmisión de elementos culturales, sociales e, incluso, proxémicos y kinésicos.

En este trabajo planteamos una reflexión sobre la variación lingüística tomando como base Terrados ${ }^{1}$, una película de bajo presupuesto rodada en Barcelona en donde la forma de hablar de los personajes nos va a servir para realizar planteamientos didácticos en torno a las variedades dialectales del español (en este caso reflejando algunos giros que muestran la interferencia lingüística con el catalán), las variedades diastráticas, presentes en cuanto a la forma de expresarse según el nivel social y edad de los personajes y, por último, las diferencias basadas en el habla, que se van a representar a través de muestras, sobre todo de carácter sintáctico y léxico, propias del lenguaje coloquial.

El cine es un poderoso recurso didáctico en la enseñanza secundaria y universitaria, por su carácter lúdico, por su carácter formativo e informativo y por las actitudes y valores que transmite (Raposo 2009: 104). También ofrece numerosas posibilidades en el aula de E/LE. Y lo hace, a nuestro juicio, a través de tres medios:

a) En primer lugar, a través de los diálogos y las voces de los personajes. Como explicaremos seguidamente con más detalle, las intervenciones lingüísticas de los personajes nos dan información sobre su procedencia geográfica, su estatus social, su profesión, etc.

b) En segundo lugar, los temas que plantea la película van a ser una fuente de conocimiento sobre los elementos culturales del país o los países en donde se desarrolla. No hay que olvidar que lengua y cultura siempre van unidas y resulta imposible (o muy difícil, al menos) enseñar una lengua sin explicar los elementos culturales y sociales en los que se basa.

c) Y, por último, a través de la caracterización de los personajes, porque poniéndoles «etiquetas» también se adquiere vocabulario acerca de la personalidad (tímido, egoísta, sincero...), las características físicas (robusto, enclenque, corpulento...) y las relaciones que establecen entre ellos (amistad, celos, competencia...).

\section{La variedad lingüística en el cine}

El primer punto está relacionado con la variación lingüística. Sabemos que el español es una lengua homogénea, pero ello no es incompatible con la existencia de variedades. Unas son de naturaleza geográfica, y son muchos los especialistas que han señalado las diferencias entre unas regiones y otras. Así, dentro de los dos grandes bloques en que podemos dividir dialectalmente el español (América y España), tenemos también subdivisiones. Por lo que se refiere a América, encontramos cinco grandes zonas: Caribe, México y Centroamérica, los Andes, Chile y la zona de la Plata y el Chaco. En cuanto a España, el español castellano, el andaluz y el canario (Moreno Fernández 2007). Menos estudiado se encuentra el español de las zonas bilingües peninsulares,

\footnotetext{
${ }^{1}$ Se puede encontrar información sobre la película (ficha técnica, crítica, tráiler, imágenes, etc.) en el siguiente enlace: https://www.filmaffinity.com/es/film692103.html
} 
aunque es evidente que existen rasgos diferenciales y que estos deben ser tenidos en cuenta en la enseñanza de la lengua (Roselló y Giménez 2017). La película Terrados tiene lugar en Barcelona y son muchos los rasgos lingüísticos del español hablado en Cataluña, tanto fonéticos (abertura de algunas vocales, suavización en la pronunciación de la $s$, que en muchos casos tiene una realización sonora), como morfosintácticos (dequeísmos, pluralización del verbo haber impersonal) y léxicos.

Las variedades de naturaleza social nos llevan a un plano sociolingüístico (sociolectos). Tal vez creamos que este aspecto tiene menos interés en el plano didáctico, ya que nuestro objetivo se centra en la enseñanza de una lengua estándar o neutra y no en la búsqueda de diferencias en cuanto a la clase social, el sexo o la edad. Pero no es así, porque la aparición de vulgarismos está relacionada en muchas ocasiones con bajos niveles de instrucción o de clases desfavorecidas socialmente ${ }^{2}$. Es normal que el cine refleje estos aspectos con personajes que muestran una manera de hablar de acuerdo con su estatus o su nivel de estudios. En la película que tomamos con referencia, Terrados, podríamos pensar que los personajes, la mayoría con formación universitaria, están en un mismo nivel social. Sin embargo, dentro de una supuesta clase media existen también escalafones (media alta, media baja) que deja también su reflejo en el comportamiento lingüístico. Los amigos, tildados de pijos por la pareja protagonista, se muestran mucho más formales en el uso del lenguaje.

Por último, las variedades diafásicas, también denominadas registros, se definen en función de la situación y el contexto comunicativos. Estamos ante un tipo de variación y de variedad lingüística, en palabras de Moreno Fernández (2007: 54), de extraordinaria importancia en la enseñanza de la lengua, ya que «el desarrollo, desde los años setenta, del llamado enfoque comunicativo ha contribuido a valorar la información relativa a situaciones y contexto», o, lo que viene a ser lo mismo, toda la información relativa a los estilos»».

Por lo que hace referencia a estas variedades de habla ${ }^{3}$, cobra especial importancia, sobre todo en niveles superiores, la enseñanza del registro coloquial. En efecto, el aprendizaje de una lengua no supone solamente el dominio del lenguaje formal, sino que se manifiesta también en la correcta adecuación del uso con la situación y el entorno comunicativo. En ocasiones, este entorno comunicativo se da en situaciones más o menos informales, en donde cobra importancia la regulación de turnos, los mecanismos de atenuación o intensificación, ciertos recursos de entonación, procedimientos fóricos o deícticos, las elipsis, los conectores, además de elementos léxicos o fraseológicos. Es decir, el lenguaje coloquial. Con ello queremos decir que el registro coloquial no solo se da en el léxico y en la fraseología (aunque, ciertamente, sean estos los primeros para iniciar el estudio de este registro) y que, por tanto, también hemos de atender a la estructura sintáctica y pragmática de la conversación.

Por ello, es necesario definir con cierta precisión el término coloquial. Briz (2001: 37) entiende por coloquial «un uso socialmente aceptado en situaciones cotidianas de

\footnotetext{
${ }^{2}$ Para identificar las clases sociales, utilizamos los criterios de Labov (1966), que atiende al grado de instrucción del hablante, la ocupación profesional, sus ingresos económicos y las condiciones de alojamiento.

${ }^{3}$ Briz (1996) insiste en que, en muchas ocasiones, se confunde el español coloquial, como nivel de habla, con los niveles de lengua. En este sentido coincide con Seco (1973: 365), quien considera que popular es un nivel de lengua y coloquial un nivel de habla. Por tanto, el español coloquial «es un registro, nivel de habla, un uso determinado por la situación, por las circunstancias de la comunicación» (Briz, 1996: 29).
} 
comunicación, no vinculado en exclusiva a un nivel de lengua determinado y en el que vulgarismos y dialectalismos aparecen en función de las características de los usuarios». Por otro lado, no hay que olvidar que nosotros trabajamos sobre una película (Terrados) y que los personajes están reproduciendo un guion previamente escrito. Algunos autores dudan sobre el carácter coloquial de estos textos, puesto que se trata de una transposición o trasplante de un nivel (coloquial) a otro (literario), y que esto nunca se puede conseguir con verdadera autenticidad. Como explica Narbona (1989: 151), siempre se lleva a cabo una adaptación, lo que conlleva una simplificación o manipulación por parte del autor. Esto implica que no se dé una autenticidad, por un lado, porque se prescinde del contexto del registro coloquial real, y, por otro, porque se vale de esta modalidad de uso para unos propósitos (realismo, caracterización de personajes, etc.) que en el empleo corriente no se dan. Sin dejar de estar de acuerdo con estas palabras, pensamos que el cine, de alguna manera, devuelve la voz al texto y lo acerca más al uso espontáneo y real.

Vamos, en primer lugar, a poner en situación a los alumnos explicando a grandes rasgos el argumento de la película Terrados. Leo acaba de perder el trabajo, al igual que la mayor parte de sus amigos, en la época más dura de la crisis económica española. Todos tienen alrededor de treinta años y están desmotivados por el entorno laboral, así que comienzan a subir a las azoteas de los edificios, donde pasan las horas sin hacer nada. Poco a poco se acostumbran a esa rutina y no son capaces de reaccionar. En medio de esta corriente de pasotismo y evasión, irán descubriendo su verdadera personalidad. Las relaciones de Leo con su novia, Ana, y con su mejor amigo, Mario, marcarán el compás de su evolución.

Es significativo el fotograma que abre la película (Imagen 1), en donde aparece el término terrado y su definición 'Azotea, terraza. Cubierta plana de un edificio, preparada para subir a ella y usarla', que nos sitúa ante la primera variable diatópica.

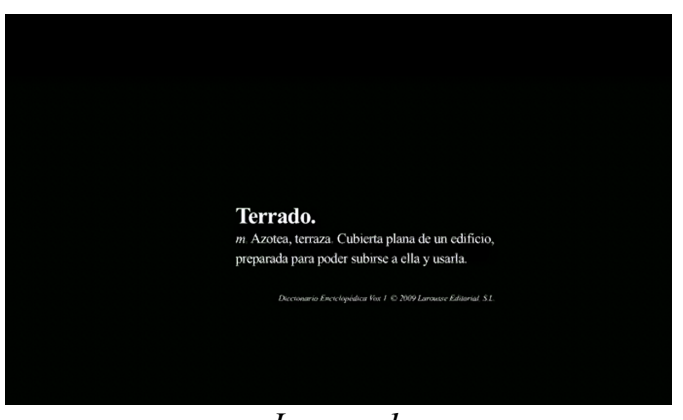

Imagen 1

En efecto, aunque el término terrado aparezca en el Diccionario de la Lengua Española, remite a terraza, y es muy utilizado en Cataluña como sinónimo de azotea. Lo que la película quiere decirnos con este primer fotograma es que terrado es la palabra que habitualmente se utiliza en Barcelona para referirse a lo que en el resto de España se conoce como azotea. Un dato que, sin duda, conviene explicar a los estudiantes que estén aprendiendo español en las comunidades bilingües del este peninsular.

A continuación, tiene lugar el primer diálogo (1) que hemos escogido para nuestro análisis. Tiene lugar entre Leo y Mario, los dos personajes principales de la película. 
Mario está al frente del despacho de abogados donde trabaja Leo. Por tanto, son compañeros de trabajo y llevan a cabo esta conversación dentro del automóvil, en un lavadero, donde comentan diversos aspectos sobre un cliente que ambos conocen.

(1) MARIO. Eh, pero que este tío, ahí donde lo ves, era un perla, ¿eh?

LEO. ¿Espriu?

MARIO. Espriu. Espriu era un perla. ¿Tú sabes lo que hacía cuando lo conocí?

LEO. No.

MARIO. El tío se montó un taller y por las noches saboteaba los coches del pueblo para conseguir clientela.

LEO. [risas] Venga, hombre, no seas animal.

MARIO. Que sí, que lo conocí así. Me llamaron un día al turno de oficio que lo habían pillao la noche anterior... Es que es pa' cagarse la anécdota. Resulta que un tío llega a su casa y se encontró a Espriu debajo del coche del vecino... y le dice: Oye, tú, ¿qué haces ahí debajo? Y Espriu sale de debajo del coche y le dice: eeeeh..., es que soy el mecánico, es que estoy arreglando un manguito.

LEO. [risas] ¡Qué dices!

MARIO. ¿A las tres de la mañana? Hostia...

LEO. Joder...

MARIO. Nada, lo demandaron, yo le llevé el caso, pasó el tiempo, y, ¡bueno!, se montó esta empresa, yo le iba asesorando, y, bueno, al cabo de un par de años, pues, la cosa empezó a funcionar bien.

LEO. ¡Joder con Espriu! Hostia, se lo ve tan tranquilo, parece.

MARIO. Ya te digo, nen. [risas] Pero, bueno, esto de que la empresa vaya bien le va a durar poco, ya verás.

LEO. ¿Por qué?

MARIO. Pues porque su hijo no se entera de una mierda y él está cansao y la hija hace lo que quiere... Es que es la misma historia de siempre. O sea, en vez de ponerlo a currar desde abajo para que sepa realmente de que va, o sea, el negocio, pues no, lo envía a la universidad, estudia una carrera y luego, pues, directamente a mandar. Bueno, ya lo has oído: las ventas están cayendo, pero él como ya está jubilao, pues le da igual.

LEO. Pues que pena, ¿no?

MARIO. Sí, es una pena, sí. Me sabe mal por él. [pausa]

MARIO. Bueno, ¿qué? ¿Tiramos o hacemos noche aquí?

LEO. [risas] Tiramos

MARIO. Tiramos

LEO. Pa' casita. Ya está bien de autolavado por un día.

MARIO. Mañana más.

En la actividad propuesta, los alumnos vieron dos veces el fragmento; luego, se comentaron y explicaron algunos rasgos sobre las distintas variedades del español, en especial, las referentes al habla. Más tarde, con el fragmento escrito, ya pudimos explicar algunos rasgos evidentes del lenguaje coloquial presentes en este fragmento. Sin ánimo de ser exhaustivos, observamos la existencia de numerosos conectores de tipo pragmático cuya función principal es la de encadenar enunciados (pero que este tío; pues porque su hijo no se entera; es que es la misma historia de siempre), intensificadores (su hijo no se entera de una mierda; es que es pa'cagarse, que sí, que lo conocí asi), mecanismos de atenuación (Venga, hombre, no seas animal), empleo de proformas (la cosa empezó a funcionar bien), expresiones interjectivas (iQué dices!; ¡Joder con Espriu!), el empleo del estilo directo, muy típico en la conversación (...Y Espriu sale de debajo del coche y le dice: eeeh..., es que soy el mecánico), presencia de enumeraciones (Nada, lo demandaron, yo le llevé el caso, pasó el tiempo y, ¡bueno!, se montó esta empresa; su hijo no se entera de una mierda y él está cansao y la hija hace lo que quiere), presencia del pronombre personal sujeto, yo, como señal de inicio de 
habla o preludio de opinión del hablante (yo le llevé el caso; yo le iba asesorando), referencias exofóricas (Oye, tú, ¿qué haces ahí debajo?), relajación articulatoria (pillao, cansao, jubilao), amalgamas y contracciones (Pa'casita). El uso de metáforas cotidianas, como Espriu era un perla, requería también alguna explicación (utilizado en sentido irónico, se dice de alguien que no es precisamente modélico en su forma de actuar o en su conducta). Hay que destacar también el regulador fático-afectivo ( $Y a$ te digo, nen), con carácter dialectal, ya que el apelativo nen se suele utilizar mucho en Cataluña, así como la expresión me sabe mal.

De igual modo, en el ámbito de la sociolingüística aplicada a la enseñanza de las lenguas han ido adquiriendo cada vez más importancia los usos lingüísticos procedentes de diferentes ámbitos profesionales (economía, derecho, medicina, turismo, etc.). Es en estos ámbitos de especialización donde se puede hablar de lenguas de especialidad, que nacen y evolucionan de forma paralela a las ciencias, las técnicas y las profesiones y que responden, como señala Aguirre Beltrán (1998), al propósito de facilitar la comunicación entre los profesionales de los más diversos y complejos campos de la actividad humana. El término lengua de especialidad remite esencialmente, según Cabré (2005), al «conjunto de los conocimientos morfológicos, léxicos, sintácticos y textuales, que, según el tema, conforman el conjunto de recursos expresivos y comunicativos necesarios para desenvolverse adecuadamente en el contexto profesional de dicha especialidad». En (2) ofrecemos un ejemplo de español con fines específicos, en concreto de la especialidad economía, extraído de «Negocios», suplemento del diario El País. En este fragmento, una de las protagonistas de la película, Elsa, lee a sus compañeros un artículo de actualidad extraído del suplemento citado, en donde se pone de manifiesto el valor del trabajo en la sociedad actual.

(2) ELSA (lee). El infarto financiero que hemos sufrido y sufrimos no ha caído del cielo. Es un resultado natural de los malos hábitos de vida y la exuberancia financiera. La centralidad en el campo de las finanzas viene necesariamente acompañada de la depreciación del valor trabajo, del valor central por antonomasia, del valor que ha cohesionado y estructurado nuestras sociedades. Solamente a partir del trabajo forma el hombre parte de la sociedad y de su proyecto. De ahí que el derecho al trabajo sea el derecho de ciudadanía por excelencia, el primer derecho. Por ello, quien pierde el trabajo ve mermado su derecho.

MARIO. Un brindis por esa última frase. Salud.

TODOS. Salud.

LEO. Oye, lo tienes muy claro, ¿no?, tú, todo esto.

ELSA. Bueno, tío, es que soy licenciada en Economía.

LEO. ¿Qué?

ELSA. Sí. No lo sabías

MARIO. ¿A que estás flipando? Yo me enteré cuando estaba dos años currando conmigo.

LEO. ¿Qué dices? ¿De verdad?

MARIO. Sí, te lo juro.

LEO. ¿Pero por qué no has currao en eso?

ELSA. Ay, no sé, porque yo siempre soñé con ser secretaria.

MARIO. Sí, y la mejor del mundo.

ELSA. Gracias, baby.

PABLO. Oye, una cosa que yo no he entendido. Eso de los activos y el trescientos por cien, ¿eso cómo está?

ELSA. Esto quiere decir que el trescientos cuarenta por ciento del valor monetario de nuestra economía está basado, pues, en acciones de mercado. No en el trabajo, no en bienes tangibles, sino, pues, en algo totalmente virtual, como son los valores de especulación. MARIO. Vamos, que estamos sobre una nube en vez de estar en la tierra. 
PABLO. O sea, que la economía la han sostenido un grupo de hijos de perra del mercado financiero y con eso lo que han hecho es joder al mercado laboral, ¿no?

MARIO. Hablas como un auténtico político, Pablito.

PABLO. Dan ganas de no volver a bajar a la calle, ¿eh?

NACHO. Oye, pues yo traigo unas setas.

MARIO. Setas ¿de qué tipo?

NACHO. Setas de buen rollito.

Los textos especializados, como pone de manifiesto Martín de Nicolás Romero (2017) se caracterizan por su vocabulario específico, que presenta los rasgos de universalidad, objetividad, claridad, precisión y verificabilidad, predominio de oraciones cortas, impersonalidad con se y pasivas reflejas, coordinadas, nominalizaciones, tiempos verbales en indicativo y presente atemporal, condicional y futuro de subjuntivo para expresar hipótesis, predominio de la tercera persona del singular, adjetivos especificativos, proposiciones subordinadas adjetivas. En (2) podemos observar el valor preciso de determinados términos aplicables al ámbito jurídico y económico (trabajo, derecho, sociedad, proyecto, ciudadanía), así como otros de carácter sintagmático (hábitos de vida, exuberancia financiera, valor central por antonomasia), el predominio de la tercera persona (es un resultado natural, quien pierde el trabajo ve mermado su derecho...), nominalizaciones (exuberancia, centralidad, depreciación...), tiempos verbales en indicativo (viene, ha cohesionado...), etc. No obstante, también podemos encontrar otros rasgos que lo alejan un poco de una formalidad excesiva, como las referencias fóricas (el plural inclusivo hemos sufrido y sufrimos), metáforas económicas, pero que ya nos son cotidianas (infarto financiero) o recursos próximos al lenguaje coloquial ( $n o$ ha caído del cielo).

Muy interesante, igualmente, es la reelaboración de este texto por parte de los personajes que intervienen en la secuencia. Obsérvese cómo Elsa, licenciada en Económicas, intenta explicar, sin abandonar el lenguaje formal (acciones de mercado, bienes tangibles, valores de especulación), lo sustancial del texto que acaba de leer, y cómo Mario reinterpreta de manera metafórica (estamos sobre una nube en vez de estar sobre la tierra que hace referencia al carácter virtual de las transacciones económicas, que ya no se producen con dinero a la vista) y oral lo que se decía antes en un texto escrito, con el marcador en vez de, más cercano a la conversación coloquial. El paso siguiente lo da otro personaje, que ya abandona el habla coloquial para situarse claramente en un lenguaje vulgar (la economía la han sostenido un grupo de hijos de perra del mercado financiero y con eso lo que han hecho es joder al mercado laboral, ¿no?), si bien esa vulgaridad es intencional, ya que el personaje se sitúa ideológica y socialmente en contra del sistema, como veremos a continuación.

\section{Los temas culturales y sociales en el cine}

En efecto, los temas que plantea la película van a ser una fuente de conocimiento sobre los elementos culturales y sociales del país donde se desarrolla. La historia que cuenta Terrados se sitúa en la España de 2011-2012, una sociedad duramente golpeada por la crisis, y coincide en el tiempo con el movimiento del 15-M y de los indignados. Ciertamente, Terrados retrata muy bien a aquellas personas entre veinticinco y cuarenta años que, aunque bien preparadas, se vieron de repente sin trabajo. Esto les generó dudas sobre lo acertado de sus elecciones personales y sobre la utilidad de los consejos 
recibidos por padres y profesores. Es lo que le ocurre, por ejemplo, a Leo, el protagonista, que se da cuenta de que nunca ha tomado decisiones por sí mismo, simplemente ha hecho lo que otros le decían.

De este modo, la película nos permite, por un lado, introducir la argumentación en las clases de E/LE, y, por otro, reflexionar sobre determinados temas sociales y compararlos con los que se producen en sus respectivos países. En (3) se plantea el tema de los estudios universitarios. Para uno de los personajes (joven), los estudios universitarios son fundamentales en cualquier proyecto laboral y no concibe iniciar una actividad sin una buena formación académica. Sin embargo, Nacho, representa el polo opuesto, ya que para él la acumulación de información bloquea la mente y coarta la creatividad de las personas. Es un debate interesante para plantear en el aula.

(3) JOVEN. Pues yo me pasaría toda la vida estudiando.

LEO. Es una buena opción.

MARIO. Sí, cojonuda.

NACHO. Pues yo no estoy muy de acuerdo. Hay obsesión por estudiar, por acumular información y esto te nubla la mente.

JOVEN. ¿No querrás decir que te la abre?

NACHO. Depende. Por ejemplo, si tú les das un lego a unos niños con sus instrucciones, todos intentarán reproducir el modelo. El que más se acerque será el mejor. Si no le das esas instrucciones, cada uno va a hacer algo distinto y original.

JOVEN. Sí, pero la universidad te da una referencia de las cosas.

NACHO. Sí, pero a veces esas referencias son engañosas. La verdadera realización personal ocurre cuando esas referencias desaparecen.

MARIO. ¡Qué profundo que estás, Nachete!

NACHO. ¡Y tú borracho, cabrón!

JOVEN. No sé, tío, hoy en día me parece imposible hacer algo si no tuvieras una carrera. NACHO. Para nada, hombre, para nada. Yo no tengo una carrera y estoy montando una empresa.

JOVEN. Pues yo no voy montando nada si no tuviera una preparación universitaria. Tengo dos carreras y voy por el doctorado.

NACHO. Tú piensa que todo lo que aprendes en la universidad, un día algún cabrón sin medios lo aprendió sin que nadie se lo enseñara. Eso es aprender de verdad.

En (4) se plantea el tema de la consideración social de las carreras universitarias y sus posibles salidas laborales. Pablo ha estudiado, Filología, carrera que tiene la consideración de poco útil a ojos de la sociedad, frente a otras como Económicas o Empresariales, que gozan de un mayor prestigio social. Por otro lado, estudios más tradicionales como Derecho, que han gozado siempre de consideración, sufren un descrédito debido al elevado número de licenciados y graduados que existen actualmente.

(4) PABLO. Pero, bueno, al final lo de siempre: mis padres se empeñaron en que hiciera una carrera útil.

ELSA. Caíste en la trampa, ¿no?

PABLO. ¡Joder, que si caí! Caí con todo el equipo.

ELSA. ¿Qué se supone que es una carrera útil?

PABLO. Pues para mis padres era Empresariales o Económicas. Pero, bueno, yo, al final, estudié Filología.

ELSA. Bueno, pero Filología esta guay, ¿no?

PABLO. Sí, mola, pero, bueno, tampoco es lo que yo quería, así que ¿de qué me sirve?

ELSA. Ya. 
PABLO. Y, luego, mis colegas, los que estudiaron Derecho... Esos están todos en el paro. Y los que no están en el paro, cobran un sueldo de mierda, viven con sus padres... Es que si no tienes novia.

ELSA. Ya. Oye, ¿y tú estás con tus padres?

PALBLO. Totalmente.

ELSA. Es que todos con máster, con carrera, pero solteros y sin curro.

PABLO. Ya veras, de aquí nada nos piden un doctorado para currar en la gasolinera.

\section{Los personajes}

Por último, como ya se ha dicho anteriormente, el cine es un estupendo recurso didáctico para aprender vocabulario relacionado con la personalidad. Se incluiría, por un lado, una selección de adjetivos aplicables a algún personaje, como se muestra en (5)

(5) Elige los adjetivos que mejor definan a Leo (Imagen 2): sociable, inseguro, perezoso, simpático, egoísta, solidario, colérico, pesimista, reflexivo, responsable, trabajador, sincero, indeciso...

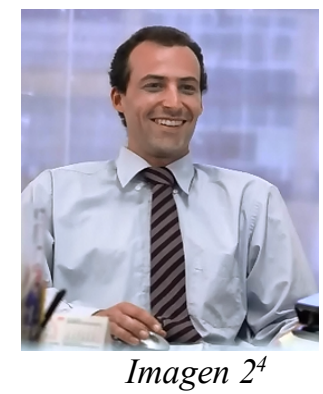

Igualmente, podríamos establecer qué vínculos se establecen entre los personajes. Por ejemplo, en (6), observamos que Mario, que es unos años mayor que Leo, reprocha a este la falta de sacrificio y de compromiso, ya que una carrera universitaria no te garantiza un trabajo y una posición en la vida. Leo escucha esta reprimenda como otras tantas que ha escuchado en su vida, sin apenas reaccionar, lo que lleva a Mario a la irritación. ¿De qué manera debería reaccionar Leo?, podíamos preguntarnos. ¿Entiende, de verdad, el mensaje que le está dirigiendo su amigo?

(6) MARIO. ¿Sabes qué pasa, Leo? ¿Sabes qué pasa? ¿No? Yo te lo digo. Lleváis el escapismo en el ADN. No afrontáis los problemas. Huis. Estudiáis una carrea. Muy bien, por gusto o, simplemente, por hacer algo, pero os lo pasáis tan de puta madre en la universidad que nunca más entendéis que en la vida hay que currar, Leo, hay que sacrificar cosas. Mira, ¿sabes lo bueno que tienen los que hoy en día no van a la universidad en este país? Que escogen con los huevos y no de la mano de papá. Nachete, por ejemplo. Nachete es un tío que tiene un objetivo, sigue un camino y no tiene estudios, ¿eh?, pero el tío está creando algo y en colaboración con más gente. Para mí, para mí Nachete se merece mucho más respeto que cualquiera con tres carreras y diez másters. Y le podrá salir bien o mal, pero nunca nadie le podrá decir que no lo ha intentao. Y menos que no lo ha luchado. Quítate las putas gafas, Leo. Mírame. Quítate las gafas. ¿Me has entendido?

LEO. Sí.

MARIO. ¿Sí?

LEO. Que sí, joder.

\footnotetext{
${ }^{4}$ Imágenes extraídas del tráiler de la película. Disponible en http://www.sensacine.com/peliculas/pelicula214530/trailer-19419460/ [Recuperado el 10 de abril de 2018]
} 


\section{Conclusión}

En suma, hemos visto que el cine puede reflejar la variación, tanto lingüística como cultural, de nuestras sociedades. Por otra parte, esa especie de microcosmos que encierra la película puede ser una vía adecuada para su aprovechamiento didáctico en el aula de E/LE. En primer lugar porque los personajes están reflejando una forma de hablar que se da también en la sociedad en la que viven, y que nos permite extraer giros dialectales de la zona donde se desarrolla la historia o de donde proceden los personajes (en este caso, de Cataluña); también podemos caracterizar su lenguaje dependiendo de variables como la edad o el estrato social (medio alto o medio bajo) y reproducir formas de habla coloquial (muy habitual en la película) o formal (entrevistas de trabajo). En segundo lugar porque la película es un reflejo de la sociedad y del tiempo que nos ha tocado vivir, y todo ello se plasma en la lengua, bien a través de los problemas laborales que atraviesan los personajes, bien a través de los conflictos sentimentales (sobre todo del personaje de Leo y su novia) y personales. La universidad, las relaciones amorosas, la amistad, el futuro laboral son temas muy próximos a los estudiantes, pero, obviamente, son vividos de manera muy distinta cuando se está residiendo fuera del país natal y se está aprendiendo otra lengua. De ahí que esa proximidad temática sea un cauce idóneo para la enseñanza de la lengua, en este caso el español, que, aunque les llega a través de unos personajes inventados, muy bien podrían estar en las calles, en los bares o en las aulas que ellos frecuentan cada día.

\section{Bibliografía}

AguirRe BeltrÁn, B (1998). «Enfoque, metodología y orientaciones didácticas de la enseñanza del español para fines específicos». Carabela, 44, 5-29.

BRIZ GÓMEZ, A. (1996). El español coloquial: situación y uso. Madrid: Arco Libros.

BRIZ GÓMEZ, A. (2001). El español coloquial en la conversación. Esbozo de pragmagramática. Barcelona: Ariel.

CABRÉ, M. T. (2005). «Recursos lingüísticos en la enseñanza de lengua de especialidad». Comunicar y enseñar a comunicar el conocimiento especializado. $V$ Jornada-coloquio de la Asociación española de Terminología (AETER). Recuperado el 10 de abril de 2018, en http://cvc.cervantes.es/lengua/aeter

GARCÍA DE ENTERRÍA, J. (2009). El español lengua de especialidad: enseñanza y aprendizaje. Madrid: Arco/Libros.

LABOV, W. (1966). The Social Estratification of English in New York City. Washington: D.C., Center of Applied Linguistics (1982, $3^{\text {a }}$ reimp.).

MARTín DE NiCOlÁs Romero, M. (2017). «La enseñanza del español lengua de especialidad». En A. M. Cestero Mancera e I. Penadés Martínez (editoras), Manual del profesor de ELE (pp. 407-455). Alcalá de Henares: Universidad de Alcalá.

Moreno Fernández, F. (2007). Qué español enseñar. Madrid: Arco Libros (2. ed.).

NARBOnA JimÉnEZ, A. (1989). Sintaxis española: nuevos y viejos enfoques. Barcelona: Ariel. 
RAPOSO RIVAS, M. (coord.) (2009). El cine en educación: realidades y propuestas para su utilización en el aula. Santiago de Compostela: Tórculo Artes Gráficas S.A.

Roselló Verdeguer, J. y D. GimÉnez FolQuÉs (2017). «El español hablado en Valencia. Interferencia lingüística y enseñanza de la lengua». Foro de Profesores de E/LE, 13, 143-153.

SECO, M. (1973). «La lengua coloquial: Entre visillos, de Carmen Martín Gaite». En El comentario de textos, I (pp. 361-379). Madrid: Castalia. 